\title{
Extradural haematoma in a child after an apparently mild head injury
}

\author{
Patrick A Nee, Barbara M Phillips, Carys M Bannister
}

Skull radiographs

should be taken

whenever the

mechanism of injury

suggests

considerable force
Departments of Paediatric

Accident and Emergency

Medicine and

Neurosurgery, Booth Hall

Children's Hospital,

Manchester M9 2AA

Patrick A Nee, senior

registrar, accident and

emergency medicine

Barbara M Phillips,

consultant paediatrician

Carys M Bannister,

consultant neurosurgeon

Correspondence to: MrNee.

$B M 7$ 1993;306:1665-6
About one million head injured patients attend accident and emergency departments each yearroughly $10 \%$ of all attenders. ${ }^{1}$ Most are fully alert and orientated on presentation with no abnormal neurological signs and their injuries may therefore be classified as mild. ${ }^{2}$ However, some patients presenting in this way have sustained a skull fracture-a major risk factor for extradural haematoma. ${ }^{3}$ Guidelines on selecting patients for radiography after head injury produced by The Royal College of Radiologists state the indications as a history of loss of consciousness or amnesia at any time, focal neurological symptoms or signs, cerebrospinal fluid or blood from the nose or ear, suspected penetrating injury, or difficulty in assessing the patient because of additional pathological findings such as stroke, seizure, or mental handicap. ${ }^{4}$ On these criteria the proportion of head injured patients referred for radiography is around $50 \%$ in most studies. ${ }^{56}$

\section{Case report}

A previously well 4 year old boy fell about one metre from a wall and struck the back of his head on concrete. He was not knocked out and got up immediately and continued playing. He did not complain of headache or visual disturbance but shortly afterwards he vomited and his mother brought him to the accident and emergency department.

On examination 30 minutes after the injury he was fully alert and orientated with a Glasgow coma score of 15. There were no abnormal neurological signs. There was a minor abrasion of the scalp in the right occipital region measuring about $1 \mathrm{~cm}$ in diameter but no evidence of contusion or laceration. The child looked pale but was otherwise normal. A skull radiograph was carried out because of the mechanism of injury and it showed a $6 \mathrm{~cm}$ linear fracture of the right occipitoparietal region (fig 1 ).

The child was referred to the admitting surgical resident but during the time he was being managed in accident and emergency department his level of consciousness deteriorated slightly, the Glasgow coma score approximately one hour after injury being estimated at 13. A neurosurgical consultation was sought and computed tomography performed, which showed a large extradural haematoma overlying the parieto-occiptal area of the right cerebral hemisphere (fig 2). The tomogram also showed a soft tissue

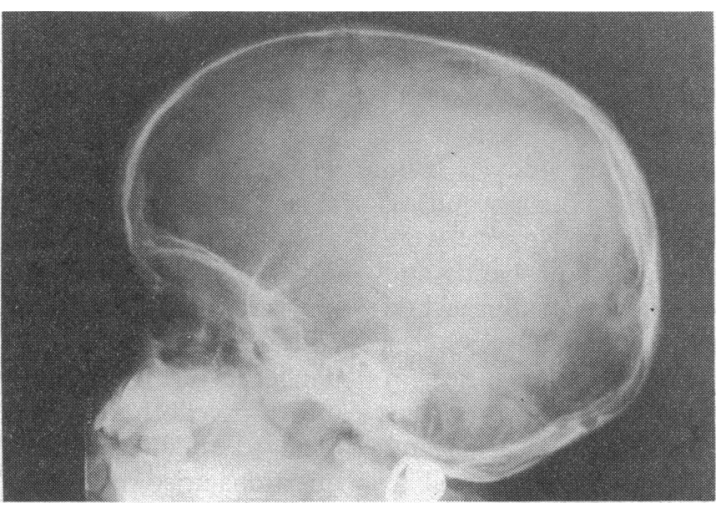

FIG 1-A $6 \mathrm{~cm}$ linear fracture of right occipitoparietal region

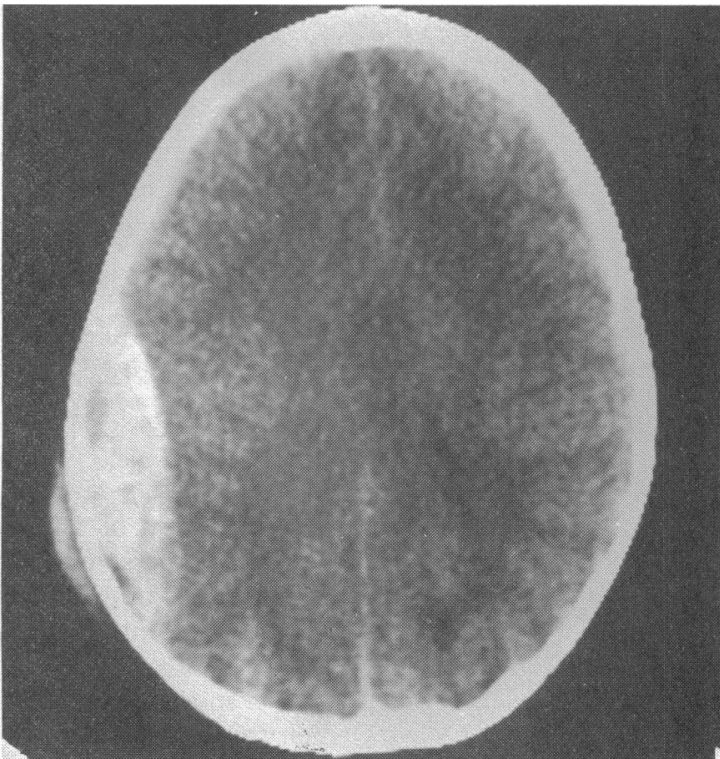

FIG 2-Extradural haematoma overlying occipitoparietal region of right cerebral hemisphere

swelling over the fracture site which did not become clinically apparent until about 90 minutes after the injury. The patient was taken to theatre and the haematoma evacuated. He made an uncomplicated recovery with no residual neurological deficits.

\section{Discussion}

Skull radiography is an essential triage tool in selecting patients for admission to hospital and for computed tomography and neurosurgical referral. Indications for radiography after head injury have been suggested by the Royal College of Radiologists. ${ }^{4}$ A group of neurosurgeons has argued that evidence of scalp bruising or swelling is also an indication for radiography. ${ }^{7}$ Others have shown that deep lacerations extending to the galea are associated with a high risk of skull fracture. ${ }^{8}$ Adherence to available guidelines will detect most skull fractures. However, skull vault fracture may occur without loss of consciousness, particularly if depressed. ${ }^{9}$ Scalp swelling or bruising takes time to develop and, furthermore, is not always a reliable guide to the presence of fracture. ${ }^{3}$

Studies using cadaveric heads have shown that skull fractures depend on the material properties of the skull and the nature of the force applied to it. Linear vault fractures occur when the head hits a broad hard surface.$^{10}$ It should therefore be possible to predict the likelihood of skull fracture by considering the physical circumstances of the injury. ${ }^{1}$

In the case described the child did not satisfy any of the usual criteria for skull radiography as laid down in the guidelines. However, an assessment of the mechanism of injury revealed that the child's head had been subjected to an impact of significant velocity against a hard surface and the risk of vault fracture was judged to be high. As a result the patient was not discharged home while harbouring an extradural haematoma.

This case supports the view of the Royal College of Radiologists that guidelines are not intended to replace 
clinical judgment. ${ }^{4}$ Following head injury the mechanism of injury, including estimated forces, should play a part in selecting patients for radiography. In addition, while it is desirable to minimise waiting times for children in accident and emergency departments, too rapid a passage through the department may prevent repeated clinical examination and can thus lead to premature discharge of patients with potential intracranial complications.

We thank Jennifer Loxley for typing the manuscript.

1 Jennett B, Murray A, McMillan R, Macfarlane J, Bentley C, Strang I, et al. Head injuries in Scottish hospitals: Scottish Head Injury Managemen Study. Lancet 1977;2:696-8.

2 Miller JD, Jones PA. The work of a regional head injury service. Lancet 1985;1:1141-4.
3 Strang I, McMillan R, Jennett B. Head injuries in accident and emergency departments at Scottish hospitals. Injury 1978;10:154-9.

4 Royal College of Radiologists. Making the best use of a department of radiology. Guidelines for doctors. London: Royal College of Radiologists, 1990.

5 Gorman DF. The utility of post-traumatic skull X-rays. Arch Emerg Med 1987;4:141-5.

6 Thillainayagam K, McMillan R, Mendelow AD, Brookes MT, Mowat W, Jennett $B$. How accurately are fractures of the skull diagnosed in an accident and emergency department? Injury 1987;18:319-21.

7 Briggs M, Clarke P, Crockard A, Cummins B, Galbraith S, Garfield J, et al. Guidelines for initial management after head injury in adults: suggestions from a group of neurosurgeons. BMF 1984;288:983-5.

8 Ballantyne E, Mendelow AD, McMillan R, Brookes M. Relationships between scalp wounds and skull fractures. IRCS Med Sci 1986;14:63-4.

Miller JD, Jennett WB. Complications of depressed skull fractures. Lancet 1968;2:991-5.

10 Gennarelli TA. Head injury in man and experimental animals: clinical aspects. Acta Neurochir Suppl 1983;32:1-13.

11 Nee PA, Hadfield JM, Yates DW. Biochemical factors in patient selection for radiography following head injury. Injury (in press).

(Accepted 16 March 1993)

\title{
Personality and fatal diseases
}

\author{
Anthony J Pelosi, Louis Appleby
}

In our review of Eysenck and Grossarth-Maticek's research on personality and disease we suggested that they may not understand just what they are claiming.' Eysenck's recent reply in this journal seems to confirm this. $^{2}$

In responding to our criticisms Eysenck outlined their hypotheses on the causes and prevention of cancer and ischaemic heart disease. But it is their claims and not their hypotheses that are under consideration. Eysenck and Grossarth-Maticek maintain they have identified personality types that increase the risk of cancer by about 120 times and the risk of ischaemic heart disease by about 25 times. They have invented a method of psychological treatment, creative novation therapy, which brings about massive reductions in death rates over the next decade. Also, a leaflet on this treatment (entitled How to Achieve Emotional Independence and a Healthy Personality) plus an explanatory introduction claims a reduction in deaths over the next 13 years in those with disease prone personalities from around $80 \%$ to $32 \% .^{34}$

We are accused of being vague in mentioning many errors, inappropriate analyses, and missing details in the publications on this research programme. We value this opportunity to be more specific, to clarify just a few of the questions raised by ourselves and others, ${ }^{5}$ which Eysenck has failed to answer, ${ }^{26}$ and to outline additional findings from these authors' investigations. $^{7.9}$

\section{The criticisms}

Firstly, Eysenck has made it clear that the trial of individual creative novation therapy (which he now calls the Maudsley intervention project $\left.{ }^{8}\right)$ involved only 192 subjects throughout, rather than 192 pairs, half of whom were lost to follow up. We note his assertion that "none of the referees considering the paper, nor the editor of the journal which published it ... had the slightest doubt about the design of the study." If he considers the following paragraph from his account of the trial, however, he may understand why we were misled: "Originally 134 pairs of type I probands and 138 pairs of type II probands had been approached with an offer of psychotherapy: of the former, one or both members refused in 34 cases, of the latter, in 46 cases, thus leaving 100 pairs of type I probands and 92 pairs of type II probands." ${ }^{4}$ The referees and editor of Behaviour Research and Therapy did well to understand the design so clearly.
Secondly, Eysenck and Grossarth-Maticek seem to have difficulty with the concept of matching. They pair matched subjects on sex and five other variables (age, smoking, cholesterol concentration, blood pressure, and personality type) and "randomly assigned one of each pair to therapy and one to the control group." Why, then, do the sex distributions in the two groups differ? ${ }^{4} 8$

Thirdly, it is useful to know that there were two surveys in Heidelberg in 1972 and only one other in 1973 "of several samples selected by different methods, the results from only some of which have been analysed." Will Eysenck now confirm that this last survey investigated 29800 subjects?

Fourthly, more details are required on the training of the " 100 or more workers who collected the original and follow up data" and on the reliability of the research interviews in their hands. The remarkable accuracy of prediction of cause of death years later would be impossible if there were the slightest misclassification of personality types. ${ }^{1011}$

Fifthly, Eysenck and Grossarth-Maticek have been criticised for not using survival analysis to present the results of their randomised controlled trials. ${ }^{12}$ They found massive differences in death rates in their two groups (treatment and control) over the ensuing decade, and these techniques would give useful information on when the divergence in mortality began.

Sixthly, the use of survival analysis techniques is not an academic nicety. It could cast some light on the relevance of a fundamental omission from the main description of their randomised controlled trial of individual creative novation therapy. ${ }^{34}$ In later publications it emerges that there was a subgroup of 41 people in their study who had type III hypertensive changes on funduscopy (including haemorrhages around the optic disc and retinal oedema) and a mean systolic blood pressure of $207.4 \mathrm{~mm} \mathrm{Hg} .{ }^{8}$ About two years later there were 51 subjects with type III retinal changes; this subgroup's mean systolic blood pressure after the creative novation therapy trial is said to be $211.7 \mathrm{~mm} \mathrm{Hg}$. We can only hope that these data are incorrect. An alternative conclusion is that Eysenck and Grossarth-Maticek have identified people with dangerously high blood pressures and entered them into a psychotherapy trial without ensuring that they received effective antihypertensive treatment. Further questions arise therefore. What methods were used to measure blood pressure? Were subjects' family doctors 